\title{
Front Matter: Volume 11848
}

, "Front Matter: Volume 11848," Proc. SPIE 11848, International Conference on Signal Image Processing and Communication (ICSIPC 2021), 1184801 (1 June 2021); doi: 10.1117/12.2600990

SPIE Event: International Conference on Signal Image Processing and SPIE. Communication (ICSIPC 2021), 2021, Chengdu, China 


\title{
PROCEEDINGS OF SPIE
}

\section{International Conference on Signal Image Processing and Communication (ICSIPC 2021)}

\author{
Siting Chen \\ Wei Qin \\ Editors
}

16-18 April 2021

Chengdu, China

Organized by

AEIC Academic Exchange Information Centre (China)

Sponsored by

ACUMINOUS RESEARCH FOUNDATION (China)

FutureLab Artificial Intelligence IBal_2 (Germany)

Published by

SPIE

Volume 11848 
The papers in this volume were part of the technical conference cited on the cover and title page. Papers were selected and subject to review by the editors and conference program committee. Some conference presentations may not be available for publication. Additional papers and presentation recordings may be available online in the SPIE Digital Library at SPIEDigitalLibrary.org.

The papers reflect the work and thoughts of the authors and are published herein as submitted. The publisher is not responsible for the validity of the information or for any outcomes resulting from reliance thereon.

Please use the following format to cite material from these proceedings:

Author(s), "Title of Paper," in International Conference on Signal Image Processing and Communication (ICSIPC 2021), edited by Siting Chen, Wei Qin, Proc. of SPIE 11848, Seven-digit Article CID Number (DD/MM/YYYY); (DOI URL).

ISSN: 0277-786X

ISSN: 1996-756X (electronic)

ISBN: 9781510645400

ISBN: 9781510645417 (electronic)

Published by

SPIE

P.O. Box 10, Bellingham, Washington 98227-0010 USA

Telephone +1 3606763290 (Pacific Time)

SPIE.org

Copyright (C) 2021 Society of Photo-Optical Instrumentation Engineers (SPIE).

Copying of material in this book for internal or personal use, or for the internal or personal use of specific clients, beyond the fair use provisions granted by the U.S. Copyright Law is authorized by SPIE subject to payment of fees. To obtain permission to use and share articles in this volume, visit Copyright Clearance Center at copyright.com. Other copying for republication, resale, advertising or promotion, or any form of systematic or multiple reproduction of any material in this book is prohibited except with permission in writing from the publisher.

Printed in the United States of America by Curran Associates, Inc., under license from SPIE.

Publication of record for individual papers is online in the SPIE Digital Library.

\section{SPIE. DIGITAL}

Paper Numbering: A unique citation identifier (CID) number is assigned to each article in the Proceedings of SPIE at the time of publication. Utilization of CIDs allows articles to be fully citable as soon as they are published online, and connects the same identifier to all online and print versions of the publication. SPIE uses a seven-digit CID article numbering system structured as follows:

- The first five digits correspond to the SPIE volume number.

- The last two digits indicate publication order within the volume using a Base 36 numbering system employing both numerals and letters. These two-number sets start with 00, 01, 02, 03, 04, 05, 06, 07, 08, 09, 0A, OB ... 0Z, followed by 10-1Z, 20-2Z, etc. The CID Number appears on each page of the manuscript. 


\section{Contents}

DIGITAL SIGNAL PROCESSING AND INFORMATION IMAGE FORMATION

1184802 Image encryption based on improved chaos and hash function [1 1848-14]

1184803 Research on super-resolution reconstruction of single frame image oriented to multi-type semantics [11848-24]

1184804 Star centroid extraction in stray light background for star sensor [1 1848-4]

1184805 Super-resolution reconstruction of image based on generative adversarial network with attention module [11848-23]

1184806 Degraded document image binarization based on U-Net and transfer learning [1 1848-53]

1184807 Research on the identification of obstacle image based on convolutional neural network [11848-51]

1184808 Hyperspectral and mutispectral image fusion via coupled block term decomposition with graph Laplacian regularization [1 1848-20]

1184809 Image denoising based on learning sparse coding network [11848-47]

$11848 \mathrm{OA}$ Chaotic image encryption algorithm based on higher and lower bit image operations [11848-40]

$11848 \mathrm{OB} \quad$ Low-illuminance color image enhancement method based on gradient domain guided filtering [1 1848-31]

$11848 \mathrm{OC}$ What's wrong with the tongue: color grading quantization based on hyperspectral images [11848-15]

11848 OD Research on cooperative signal and information processing in wireless sensor network [11848-52]

11848 OE Dispersive selected mapping without side information for PAPR reduction in FBMC/OQAM [1 1848-3]

11848 OF Research on image reliable transferring and compression based on coding theory [11848-41]

11848 OG Low-light image enhancement based on deep convolutional neural networks [11848-55]

$11848 \mathrm{OH} \quad$ Densely connected convolutional networks for breast cancer histopathological image classification [11848-27] 
11848 Ol Hyperspectral anomaly detection with nonlocal self-similarity prior [1 1848-59]

11848 0J Real-time video stitching system using parallel architecture [1 1848-22]

11848 OK Novel polarization-maintaining fiber sensor based on magneto-optical modulation for transverse pressure measurement [11848-44]

\section{FACE RECOGNITION AND REMOTE SENSING SURFACE MODELING AND SIMULATION}

$11848 \mathrm{OL} \quad$ Binocular monitoring method based on fisheye lens camera [1 1848-65]

11848 OM An improved 3D human model reconstruction technique based on Cascade MVSNet [1 1848-63]

11848 ON Cross-domain infrared target recognition based on simulation [11848-11]

1184800 Research on face recognition technology based on KPCA and SVM under convolutional filtering [1 1848-42]

11848 OP Extracting ground object information from remote sensing images based on DeepLabv3+ model integrating dual attention mechanism [1 1848-54]

$118480 Q \quad$ Design of NFC tag read-write system based on FPGA [1 1848-33]

11848 OR Background prediction applied in the correction of defective pixels based on FPGA [1 1848-72]

11848 OS Improved SRCNN remote sensing image spatio-temporal fusion based on multi-stream data input and attention mechanism: taking Landsat8 and MODIS remote sensing images as examples [11848-61]

11848 OT Radar jamming classification and recognition technology based on deep learning [1 1848-57]

11848 OU Discrimination of active false targets in distributed multiple-radar system [1 1848-37]

11848 OV Brain tumor segmentation based on multi-scale superpixel and kernel low-rank representation [1 1848-45]

11848 OW A simulation model of back-projection based non-line-of-sight imaging (NLOS) for resolution analysis [11848-16]

11848 OX Remote sensing plot segmentation and extraction based on few samples [11848-70]

11848 OY An improved IHS fusion method of GF-2 remote sensing images [1 1848-56]

$118480 Z$ Visual roughened sensing for private human pose recognition [1 1848-38] 
$1184810 \quad$ High-voltage experiment virtual simulation training system based on virtual reality [1 1848-64]

1184811 Adaptive LOD representation of terrain model based on quad-tree [1 1848-36]

1184812 Design of handwritten digit recognition system based on FPGA [1 1848-26]

1184813 Two level complex image method for periodic Green's function in scattering problem of periodic rough surface [1 1848-1]

$1184814 \quad$ Face mask recognition based on object detection [11848-69]

1184815 Detection and autonomous landing of insulators by light and small UAV based on deep learning [1 1848-46]

1184816 HUSC: a local feature descriptor of point cloud based on hemisphere neighborhood [1 1848-17]

\section{COMMUNICATION NETWORK TECHNOLOGY AND DATA ALGORITHM APPLICATION}

1184817 Timing and carrier synchronization algorithm of MQAM signal [1 1848-60]

1184818 Image steganography algorithm based on image colorization [1 1848-62]

1184819 Research on the security of communication network based on 5G technology [11848-67]

$118481 \mathrm{~A} \quad$ Muller matrix of medium based on polarized light and its polar decomposition calculation [1 1848-10]

11848 1B Deep CNN with batch renormalization based channel estimation algorithms [1 1848-66]

11848 1C Multi-level quantization method for suppressing interrupted-sampling repeater jamming [11848-5]

11848 1D Flame detection method based on improved YOLO-v3 [1 1848-43]

11848 1E CNN-HKNN for osteoporosis magnetic resonance imaging classification with data augmentation [11848-71]

$11848 \mathrm{lF} \quad$ Calculation of the vaulted magnetic field over a ship based on magnetic dipole equivalence [1 1848-18]

$118481 G$ Development of ultra-wideband multiplex synthesis technology [1 1848-35]

$118481 \mathrm{H} \quad$ Algorithm of infrared-polarization image fusion based on fireworks algorithm [11848-19]

$1184811 \quad$ TCP-BQLP: congestion control algorithm based on buffer queve length prediction in LEO satellite network [1 1848-6] 
$118481 \mathrm{~J} \quad$ Efficient wideband DOA estimation method in the presence of mutual coupling [11848-48]

$118481 \mathrm{~K} \quad$ Semi-distributed load balancing routing algorithm based on LEO satellite networks [11848-9]

$118481 \mathrm{~L} \quad$ License plate extraction and character segmentation in haze weather [1 1848-49]

$118481 \mathrm{M} \quad$ FPGA-based fuse muzzle induction setting method [1 1848-30]

$118481 \mathrm{~N} \quad$ Evaluation of optical camouflage effect based on entropy weight TOPSIS method [11848-32]

$1184810 \quad$ Study of alternant-channel chaotic secure communication system and its chaos alternant coding [1 1848-25]

11848 1P Single-scale motion blur kernel estimation method based on continuous double frames [1 1848-29]

$118481 Q \quad$ An FPGA-based efficient architecture for accelerating large-scale matrix multiplication [1 1848-28] 